\title{
Pharmaciana
}

Vol.10, No.3, Nov 2020, Page. 289-296

ISSN: 2088 4559; e-ISSN: 24770256

\section{Prediction of diacerein inhibition activity against interleukin-1 receptors through docking method and tracing of pharmacokinetic profiles and their toxicity}

\author{
Frengki $^{*}{ }^{1}$, Vivi Sofia ${ }^{2}$, Deddi Prima Putra ${ }^{3}$, Fatma Sri Wahyuni ${ }^{3}$, \\ Daan Khambri ${ }^{4}$, Henni Vanda ${ }^{1}$ \\ ${ }^{I}$ Faculty of Veterinary Medicine, Syiah Kuala University, Banda Aceh \\ Jl. Tgk Hasan KruengKalee No.4, Kopelma, Darussalam, Banda Aceh, Indonesia \\ ${ }^{2}$ Faculty of Pharmacy, Ahmad Dahlan University, Yogyakarta, Indonesia \\ Jl. Prof.Dr. Soepomo, Janturan, Yogyakarta, Indonesia \\ ${ }^{3}$ Faculty of Pharmacy, Andalas University, Padang \\ Jl. Limau Manis, Kec. Pauh, Kota Padang, West Sumatera, Indonesia \\ ${ }^{4}$ Faculty of Medicine, Andalas University, Padang, \\ Jl. Limau Manis, Kec. Pauh, Kota Padang, West Sumatera, Indonesia
}

\begin{abstract}
IL-1 is one of the cytokines involved in joint diseases such as osteoarthritis. IL-1 plays a role in maintaining the balance of proteolytic proteins: MMPs and TIMPs inhibitors. Increased expression and uncontrolled IL-1 activity tend to increase the role of MMPs in degrading proteoglycans and joint tissue collagen. This study aims to reveal the interaction model of one of the osteoarthritis drugs, namely diacerein. A drug belongs to a group of disease-modifying osteoarthritis drugs (DMOADs) to suppress the development of the disease rate, improving the structure and function of the cartilage and surrounding tissue. "In silico" digital test uses the technique of "molecular docking: used as a method of the approach using the MOE 2007.09 software application. The test material was in the form of a diacerein 3D structure and five control ligands, while the IL-1 $\beta$ / IL-1RI receptor template was downloaded from pdb.org (PDB ID: 1ITB). The ligand pharmacokinetic profile will also be displayed obtained through the ADMETSAR server. The docking results showed diacerein had the lowest docking score of $-12.3285 \mathrm{kcal} / \mathrm{mol}$ with the strongest affinity, the best pharmacokinetic profile but more toxic. This study proves that the mechanism of diacerein inhibition of IL-1 / IL-1RI receptors is similar to dexamethasone, prednisolone, and minocycline.
\end{abstract}

Keywords: Diacerein, osteoarthritis, IL-1, in silico

\footnotetext{
*Corresponding author:

Frengki

Faculty of Veterinary Medicine, Syiah Kuala University

J1. Tgk Hasan KruengKalee No.4, Kopelma, Darussalam, Banda Aceh, Indonesia

Email:frengki_fkh@unsyiah.ac.id
} 


\section{INTRODUCTION}

Osteoarthritis is an inflammatory disease of the knee, hip, and finger joints characterized by the occurrence of degradation and inflammation of connective tissue, joint-prone layers, synovium, and subchondral bone. The pathogenesis involves many genes: Tumor necrosis factor-alpha (TNF- $\alpha$ ), Interleukin-1 (IL-1), and Interleukin-6 (IL-6) are several included genes (Fernández-moreno et al., 2008).

IL-1 is activated by several proinflammatory cytokine production lines such as p38 MitogenActivated Protein Kinase (MAPK), Extracellular signal Regulated Kinases (ERK), Protein Kinase C (PKC), Nuclear Factor Kappa $\beta$ (NF-k $\beta$ ) (Weber et al., 2014) (Sripathy et al., 2012). IL-1 plays a role in regulating MMP catalyst enzymes and TIMPs inhibitors; the condition of osteoarthritis occurs characterized by an increase in uncontrolled IL-1 activity so that MMP expression increases. IL-1 $\beta$, one of the IL-1 family, is the main cytokine that stimulates COX-2 expression during inflammation (Halim and Jawad, 2015; Hopade et al., 2015).

Diacerein is one of the drugs, included in the disease-modifying osteoarthritis drug group (DMOADs), which aims to suppress the development of the disease rate, improving the structure and function of the cartilage and surrounding tissue (Sofia et al., 2018). Diacerein has a rhein structure, which is a molecule with anthraquinonic ring. This structure is known to have anti-inflammatory activity by inhibiting interleukin-1, a cytokine that is highly involved in cartilage's degenerative process. This inhibition has been confirmed in vitro and in vivo (Martel-pelletier and Pelletier, 2010).

Diacerein has been shown to be able to suppress the activity of catalytic protein MMPs, on the contrary, increase the expression and function of TIMPs in primary cells of osteoarthritis patients (Sofia et al., 2018). This effect is thought to occur through an inhibitory mechanism of IL-1 function and expression. Therefore it is necessary to prove with the in silico method or what is known as digital experiments through molecular docking techniques. This method is commonly used as a first step in cutting procedures for clinical trials to be directed and more efficient.

In this study, the molecular docking diacerein aimed to confirm its inhibitory mechanism against IL-1 receptors, one of the target proteins for patients with OA. ADME toxicity prediction is done to compare the adsorption profile, distribution, metabolism, excretion, and toxicity of diacerein with other compounds that have the same target protein.

\section{MATERIALS AND METHODS Materials}

Pharmacokinetic profiles were predicted using the ADME-Toxicity method through the ADMETSAR server (http://lmmd.ecust.edu.cn:8000/predict/) (Awaluddin et al., 2017). The series of processes and visualization of docking results are done through the MOE software application. The observed compound was diacerein, a drug that has been used to treat osteoarthritis; while the control compounds include dexamethasone, prednisolone, colchicine, minocycline, chloroquine. The template receptor is IL-1 $\beta$ / IL-1RI, one of the proinflammatory cytokines downloaded from pdb.org (PDB ID: 1ITB)

\section{Methods}

The pharmacokinetic profile of all ligands was predicted in silico through the ADME-Toxicity method, which included observations of predicted adsorption, metabolic, distribution, excretion, and toxicity values. Then proceed with observations of the prediction of the affinity of all these ligands through molecular docking techniques. Before the molecular docking process is carried out, both ligands and enzymes are prepared and optimized for their 3-dimensional structure by adding hydrogen, removing water molecules, adding partial charges, and minimizing energy. After the process is completed, the site binding selection is based on articles (Halim and Jawad, 2015) through the MOE default system. Then proceed with the docking process through site binding that has been designed. 
The docking receptor-ligand complex is stored in the PDB format, while the docking value is stored in the MDB format. The docking results are then analyzed, visualized by the 2D structure through LigPlot and the 3D structure using the MOE software application.

\section{RESULTS AND DISCUSSION}

Prediction of ligand pharmacokinetic profile

ADMET evaluation is needed to determine the pharmacokinetic profile of a drug compound. The evaluation includes identification of adsorption, distribution, metabolism, excretion, and toxicity. All pharmacokinetic parameters are shown in Tables 1, 2, and 3 below.

Table 1. Predicted results of adsorption and bioavailability parameters of test and control ligands

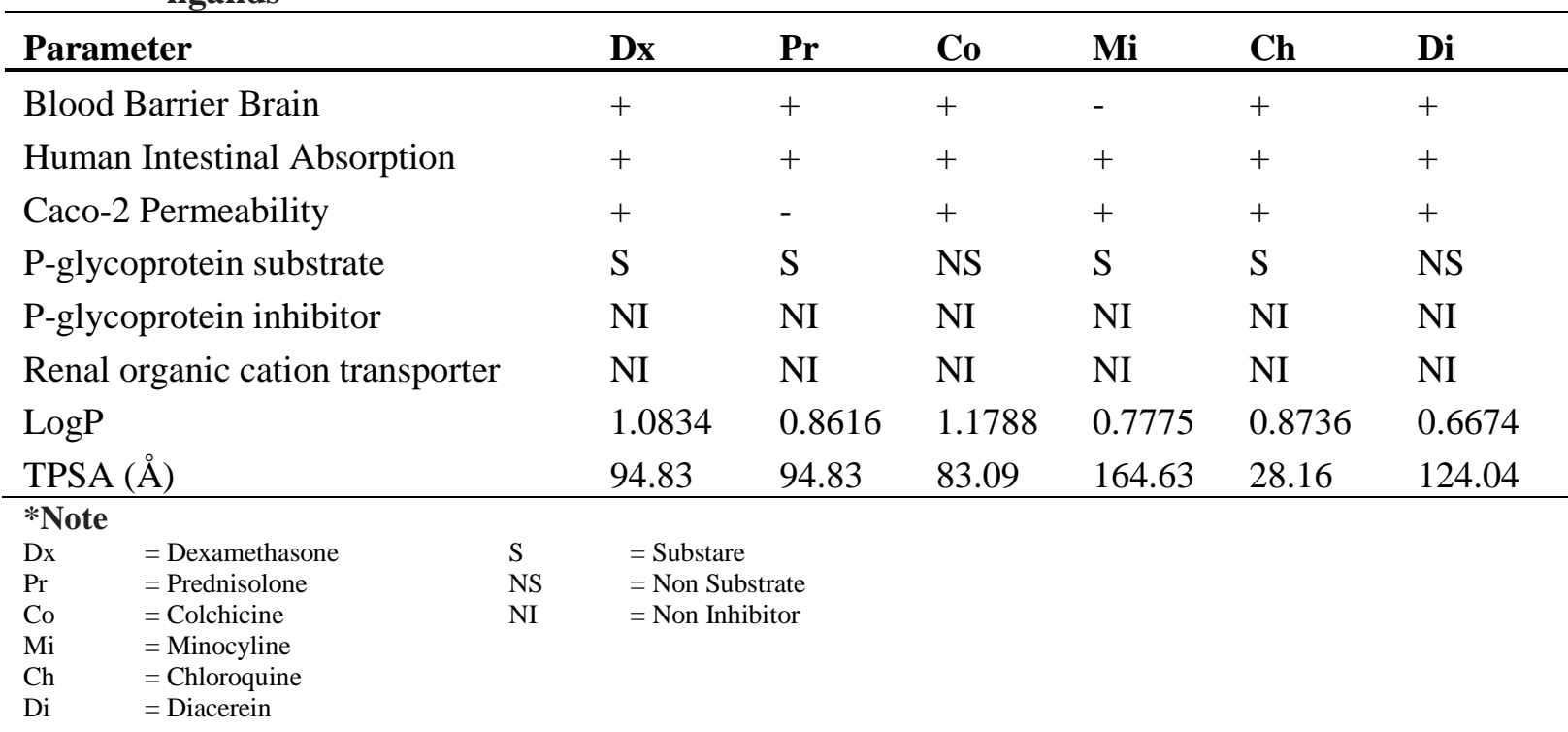

Table 2. Predicted results of test and control ligand metabolism parameters

\begin{tabular}{lllllll}
\hline Parameter & Dx & Pr & Co & Mi & Ch & Di \\
\hline CYP450 2C9 Substrate & NS & NS & NS & NS & NS & NS \\
CYP450 2D6 Substrate & NS & NS & NS & NS & S & NS \\
CYP450 3A4 Sunstrate & S & S & S & S & S & NS \\
CYP450 1A2 Inhibitor & NI & NI & NI & NI & NI & I \\
CYP450 2C9 Inhibitor & NI & NI & NI & NI & NI & NI \\
CYP450 2D6 Inhibitor & NI & NI & NI & NI & NI & NI \\
CYP450 2C19 Inhibitor & NI & NI & NI & NI & NI & NI \\
CYP450 3A4 Inhibitor & NI & NI & NI & NI & NI & NI \\
\hline
\end{tabular}


Table 3. Predicted results of test and control ligand toxicity

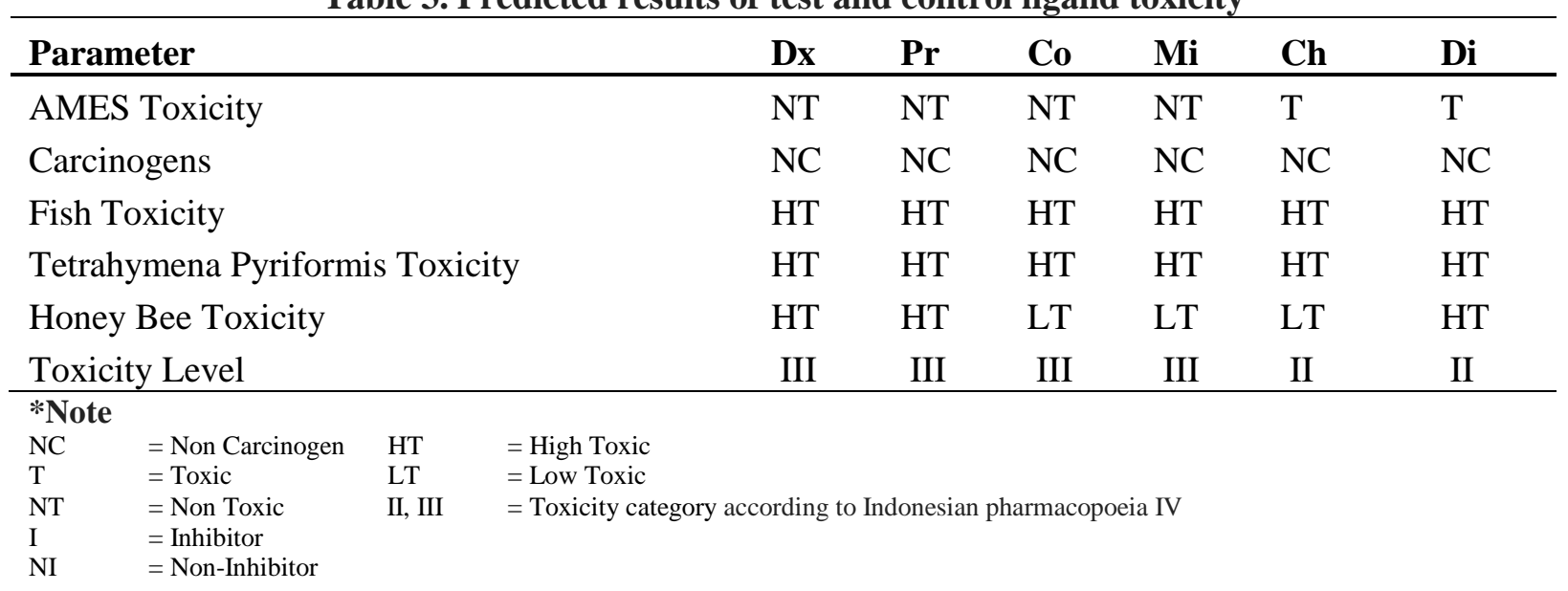

Each drug compound has physicochemical characteristics that affect its pharmacokinetic profile. The process of adsorption of compounds is influenced by several factors, such as lipophilicity, hydrogen bonds, molecular size, and pKa charge (Lawson et al., 2013). Drug compounds ideally have physicochemical properties balanced between their hydrophilicity and lipophilicity so they can penetrate the cell membrane and bind to the target receptor. Cell membranes tend to be lipophilic because of their phospholipid content, whereas cytosols tend to be hydrophilic in nature that contains protein and water.

The partition coefficient (Log P) and Topological Polar Surface Area (TPSA) are the parameters used to assess compound lipophilicity. $\log \mathrm{P}$ is one of the lipophilic parameters to show the condition of the existence of drug molecules in nonpolar and polar solvents. Meanwhile, the Topological Polar Surface Area (TPSA) is a descriptor that was shown to correlate well with passive molecular transport through membranes. Log P value of natural compounds with value $<5$ is known to be an acceptable limit, while TPSA of $\leq 140 \AA$ can be said to have Good bioavailability (Malik et al., 2019). Diacerein used in this study met the requirements as lipophilic compounds because it had log P (0.6674) and TPSA (124.04 $\AA$ ) (Table 1). These two parameters can explain that oral absorption of diacerein through the gastrointestinal meets good absorption criteria.

Diacerein also inhibits the activity of one of the cytochrome P450 (CYP450 1A2) metabolic enzymes (Table 2), which will cause changes in the concentration of other drugs metabolized by this enzyme. Hence, consideration needs to be given when administering a combination of drugs. Diacerein is also not a substrate of Pgp protein. Pgp is a protein transporter that works as a "drug efflux" that immediately ejects back compounds that enter the cell to the outside of the cell. The intracellular concentration of these compounds becomes low. This condition causes the drug's effectiveness to be suboptimal, triggering resistance and unexpected side effects (Siddik, 2003; Svetlana et al., 1998). In breast cancer cases, $\pm 50 \%$ resistance was reported due to the role of this Pgp protein (Bansal et al., 2014). The use of doxorubicin as first-line chemotherapy for breast cancer apparently triggers resistance through overexpression of Pgp protein (Bao et al., 2012). In joint disease cases, some anti-inflammatory drugs are also known to be a substrate of Pgp. Methotrexate, leflunomide, azathioprine, auranofin, and glucocorticoid classes are some of the anti-inflammatory drugs identified as substrate Pgp. The intracellular concentrations of all these drugs are low due to Pgp cells being pumped out immediately. This condition causes "impaired drug uptake" events (Jensen et al., 2003). 
In diacerein, this condition will not occur so that treatment can be done optimally, and the risk of resistance can be avoided. But even though diacerein turned out to be a relatively lower level of safety compared to the control ligand compound dexamethasone, prednisolone, minocycline, and colchicine (Table 3).

\section{Prediction of affinity through the molecular docking method}

Before the molecular docking process is done, two potential site bindings are obtained based on the default MOE tracking system. Docking scores of diacerein and five control ligand compounds (dexamethasone, prednisolone, colchicines, minocycline, and chloroquine) show a strong enough affinity for IL-1 $\beta$ / IL-1RI receptors (PDB code. 1ITB). All of them showed a tendency to release energy when forming complexes with IL-1 / IL-1RI receptors, but their affinity strength was different. The more negative the docking score obtained indicates its stronger affinity with the receptor (Frengki et al., 2018). Diacerein showed the strongest affinity marked by the docking score of $12.1669 \mathrm{kcal} / \mathrm{mol}$ at site binding $\mathrm{A}$ and $-11.3525 \mathrm{kcal} / \mathrm{mol}$ at site binding $\mathrm{B}$. Then, successive dexamethasone, prednisolone, colchicine, minocycline, and chloroquine sites with score docking scores were followed. Each of $-10.3866 \mathrm{kcal} / \mathrm{mol},-10.5626 \mathrm{kcal} / \mathrm{mol},-10.3809 \mathrm{kcal} / \mathrm{mol},-11.3506$ $\mathrm{kcal} / \mathrm{mol}$ and $-9.9317 \mathrm{kcal} / \mathrm{mol}$. The complete results of the docking are shown in Table 4.

Table 4. Molecular Docking Results of diacerein and five control ligands at the site binding "A" and "B" receptor target (PDB: 1ltb)

\begin{tabular}{|c|c|c|c|}
\hline \multicolumn{4}{|c|}{ Site Binding "A" } \\
\hline & Docking results & Hydrogen-Bond & Bond distance \\
\hline \multirow{4}{*}{ Dexamethason } & -10.3866 & Lys 114 H-Don & 2.95 \\
\hline & & Thr 147 H-Don & 1.77 \\
\hline & & Ser 13 H-Don & 1.75 \\
\hline & & Thr 147 H-Acc & 1.77 \\
\hline \multirow[t]{5}{*}{ Prednisolone } & -10.5626 & Asp 12 H-Don & 3.31 \\
\hline & & Ser 13 H-Don & 2.66 \\
\hline & & Thr 147 H-Don & 2.55 \\
\hline & & Gly 122 H-Acc & 2.70 \\
\hline & & Thr 147 H-Acc & 2.55 \\
\hline Minocycline & -11.3506 & Arg 163 H-Acc & 2.82 \\
\hline Chloroquine & -9.9317 & & \\
\hline Diacerein & -12.3285 & Arg $11 \mathrm{H}-\mathrm{Acc}$ & 2.17 \\
\hline \multicolumn{4}{|c|}{ Site Binding "B" } \\
\hline \multirow[t]{5}{*}{ Colchicine } & -10.3809 & Gln15 H-Acc & 2.75 \\
\hline & & Thr 147 H-Acc & 2.25 \\
\hline & & Thr 147 H-Acc & 2.12 \\
\hline & & Arg 163 H-Acc & 2.55 \\
\hline & & Arg 163 H-Acc & 3.35 \\
\hline \multirow[t]{2}{*}{ Diacerein } & -11.3525 & Ser 13 H-Don & 2.59 \\
\hline & & Arg 163 H-Acc & 2.86 \\
\hline
\end{tabular}


The interaction of diacerein with IL-1 / IL-1RI receptors is visualized as in Figure 1.

Site

Binding

A

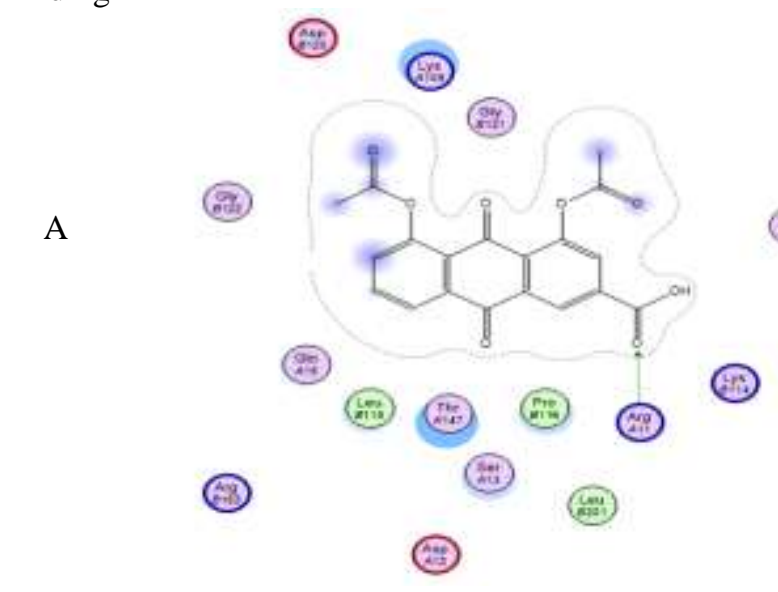

::0

2D Structure

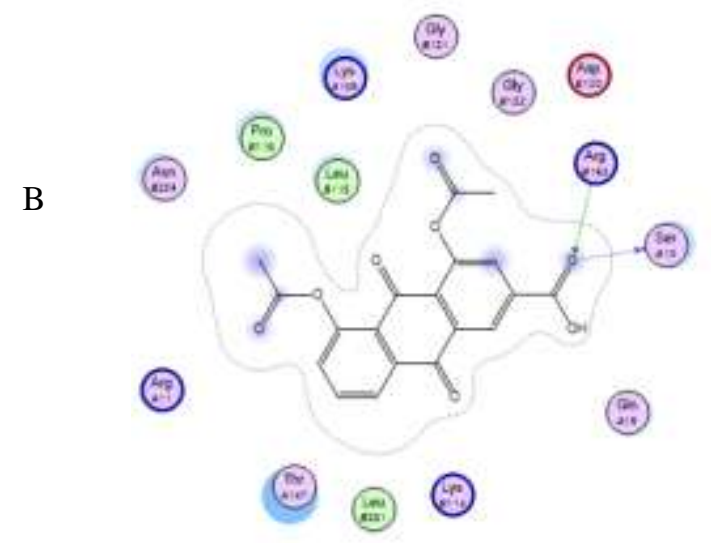

(49)
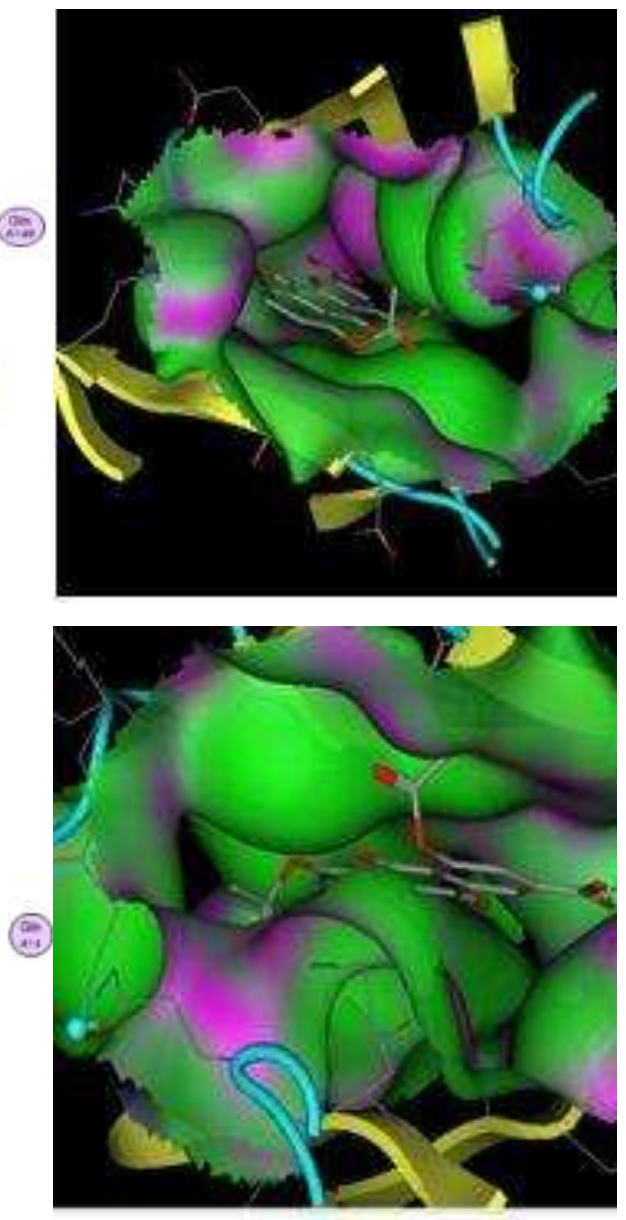

Figure1. 2D dan 3D structure of diacerein after docking at the site binding " $A$ " and "B" receptor target (PDB: 1ltb)

These docking results are in line with Halim and Jawad's (2015) report at the same binding site residues except in colchicine ligands. Ser 13, Thr 147, and Arg 163 residues are most commonly identified as interacting with IL-1 $\beta$ / IL-1RI receptors (PDB: 1ITB) to form hydrogen bonds, while (Halim and Jawad, 2015) report does not explain the type of bonding of the complex formed.

The diacerein test ligand has the same interaction pattern with the dexamethasone and prednisolone control ligands at binding site A and the minocycline control ligands at binding site $\mathrm{B}$. It is suspected that diacerein has the same inhibitory mechanism as the three control ligand compounds in the IL-1 receptor. The strength of diacerein binds to IL-1 / IL-1RI receptor is better than the three control ligands (Table 4). Diacerein only forms 1 hydrogen bond with site binding "A" (Arg 163), while dexamethasone control forms 4 hydrogen bonds (Lys 114 residue, $2 \operatorname{Trr} 147$ and Ser 13). Likewise, prednisolone control forms 5 hydrogen bonds (Asp 12, 2Thr 147, Ser 13, and Gly 122). As 
well as colchicine as a control on the site binding "B" which forms 5 hydrogen bonds (Gln 15, 2 Thr 147 and 2 Arg 163). However, diacerein's affinity was stronger than the two controls, presumably due to the hydrophobic interaction between diacerein and IL-1 $\beta$ / IL-1RI receptors. This is marked by the "pocket" site binding area "A" and "B" covered by hydrophobic residues (green in 3D structure).

\section{CONCLUSION}

Diacerein showed a better pharmacokinetic profile compared to 5 compounds with the same target protein (IL-1 $\beta$ / IL-1RI receptor inhibitors). However, diacerein showed a tendency for toxic properties to be stronger. Diacerein also showed the best docking score than the five compounds that indicated the strongest affinity as IL-1 / IL-1RI receptor inhibitors. This in silico research confirms the role of diacerein as one of the drugs of choice to overcome osteoarthritis.

\section{REFERENCES}

Awaluddin, R., Muhtadi, W. K., Chabib, L., \& Ikawati, Z. (2017). Molecular docking and ADMEtoxicity studies of potential compounds of medicinal plants grown in Indonesia as an antirheumatoid arthritis Molecular Docking and ADME-Toxicity Studies of Potential Compounds of Medicinal Plants Grown In Indonesia as An Anti. AIP Conference Proceedings, 020033, 0200331-020033-020039. https://doi.org/10.1063/1.4978106

Bansal, T., Jaggi, M., Khar, R. K., Institutes, B. S. A. E., Talegaonkar, S., \& Sciences, D. P. (2014). Emerging Significance of Flavonoids as P-Glycoprotein Inhibitors in Cancer Chemotherapy Emerging Significance of Flavonoids as P-Glycoprotein Inhibitors in Cancer Chemotherapy. Journal of Pharmacy and Pharmaceutical Sciences, 12 (1)(May), 46-78. https://doi.org/10.18433/J3RC77

Bao, L., Hazari, S., \& Mehra, S. (2012). Increased expression of P-glycoprotein and doxorubicin chemoresistance of metastatic breast cancer is regulated by miR-298. The American Journal of Pathology, 180(6), 2490-2503. https://doi.org/10.1016/j.ajpath.2012.02.024

Fernández-moreno, M., Rego, I., Carreira-garcia, V., Blanco, F. J., \& Coruña, A. (2008). Genetics in osteoarthritis. Current Genomics, 9(8), 542-547.

Frengki, Putra, D. P., Wahyuni, F. S., \& Khambri, D. (2018). Uji in vitro dan in silico senyawa 5,7,2',5'-tetrahydroxy flavan-3-OL terhadap enzim alpha glucosidase. Jurnal Fitofarmaka Indonesia, 5(2), 279-283.

Halim, S. A., \& Jawad, M. (2015). Attempt to explore the binding mechanism of IL-1 $\beta$ Inhibitors via molecular attempt to explore the binding mechanism of IL-1 $\beta$ inhibitors via molecular docking studies. Medical Chemistry, 5(10), 452-257. https://doi.org/10.4172/2161-0444.1000300

Hopade, A. R. C., Ayyad, F. J. S., \& Ore, Y. V. P. (2015). Molecular docking studies of phytocompounds from the phyllanthus species as potential chronic pain modulators. Scientia Pharmaceutica, 83(2), 243-267. https://doi.org/10.3797/scipharm.1408-10

Jansen, G., Scheper, R. J., \& Dijkmans, B. A. C. (2003). Multidrug resistance proteins in rheumatoid arthritis, role in disease- modifying antirheumatic drug efficacy and inflammatory processes: An overview Multidrug resistance proteins in rheumatoid arthritis, role in disease-modifying antirheumatic drug ef. Scandinavian Journal of Rheumatology, 32(May), 325-336. https://doi.org/10.1080/03009740310004333

Lawson, M. A., Parrott, J. M., Mccusker, R. H., Dantzer, R., Kelley, K. W., \& Connor, J. C. O. (2013). Intracerebroventricular administration of lipopolysaccharide induces indoleamine-2 , 3-. Journal of Neuroinflammation, 10(1), 1-9. https://doi.org/10.1186/1742-2094-10-87

Malik, A., Afaq, S., El-gamal, B., Ellatif, M. A., Hassan, W. N., \& Dera, A. (2019). Molecular docking and pharmacokinetic evaluation of natural compounds as targeted inhibitors against Crz1 protein in Rhizoctonia solani. 15(4), 277-286. https://doi.org/10.6026/97320630015277

Martel-pelletier, J., \& Pelletier, J. (2010). Effects of diacerein at the molecular level in the osteoarthritis disease process. Therapeutic Advances in Musculoskeletal Disease, 2(2), 95-104. 
https://doi.org/10.1177/1759720X09359104

Siddik, Z. H. (2003). Cisplatin: mode of cytotoxic action and molecular basis of resistance. Oncogene, $22,7265-7279$.

Sofia, V., Ali, H., Rahmadian, R., \& Amita, F. (2018). Ekspresi gen tissue inhibitor metalloproteinase1 pada sel sinoviosit osteoartritis grade IV setelah pemberian diacerein. Jurnal Kesehatan Andalas, 7(1), 19-25.

Sripathy, R., Anjana, D., Somashekara, N., Krishnaraju, A., Krishanu, S., Murali, M., Verma, S. R., \& Ramchand, C. N. (2012). In Silico , in vitro and in vivo assessment of safety and antiinflammatory activity of curcumin research and development, Laila Pharmaceuticals Pvt . Ltd ., Chennai , Tamilnadu, India Research and Development, Laila Impex R and D Centre, Vijayawada ,. American Journal of Infectious Diseases, 8(1), 26-33.

Svetlana, E., John, R., Fruehauf, P., Kim, A. H., Stroup, R., \& Although, I. (1998). Levels taxol of Multidrug Breast and Doxorubicin 'Resistance Cancer with in Vitro Expression to by Human Correlate Resistance. Clinical Cancer Research, 4(February), 389-398.

Weber, M. A., Schiffrin, E. L., White, W. B., Mann, S., Lindholm, L. H., Kenerson, J. G., Flack, J. M., Carter, B. L., Pharm, D., Materson, B. J., \& Ram, C. V. S. (2014). Clinical practice guidelines for the management of hypertension in the community a statement by the american society of hypertension and the international society of hypertension. Journal of Clinical Hypertension, 16(1), 14-26. https://doi.org/10.1111/jch.12237 